\title{
KEYNESIANISM VS. CLASSICAL ECONOMIC THEORY: EUROPEAN REFUGEE CRISIS AND THE FALL OF MULTICULTURALISM
}

\author{
Aliaksei PATONia \\ (c) \\ School of Geography and Geosciences, University of St Andrews, \\ MB 20 Deans Court, North Street, KY16 9QT, St Andrews, Scotland, UK \\ E-mail address: aip4@st-andrews.ac.uk
}

\begin{abstract}
Posing arguments against statistical evidence picturing the European Union as the key world economy, the research views the economic model of the EU through the prism of Hofstede's cultural dimensions, explaining its lower resistance towards the global economic crisis and comparing it to China - a country with authoritarian governmental methods - that suffered to a significantly lesser extent. Based on the example of these two entities, the paper views the topic of the current refugee crisis in Europe representing it as a new crucial trial for the EU that potentially checks classical economic theory for consistency. According to the author, if found effective, in the foreseeable future it will form a sound basis for further development, if not - it will likely be replaced by the Keynesian paradigm. Thus, with the current refugee crisis in Europe, the author juxtaposes liberal economy with the state-regulated one. This is done to give hints at the importance of the crisis per se, as it is believed to be capable of shattering some of the fundamental principles of the current world order.
\end{abstract}

Key words: European Union, global economic crisis, Fukuyama, Hofstede, cultural dimensions, liberal democracies, Keynesianism, classical economic model, refugees

\section{INTRODUCTION}

Historically, the dissolution of the Soviet Union and demise of communism in Europe tie in closely to the creation of the European Union under the provisions of the Maastricht Treaty. Since then, the community of liberal democratic nations of Old Europe has managed to integrate a great number of countries, formerly associated with the Eastern Block. Even though some researchers view this amalgamation of nations with different economic, historical and political backgrounds with a great skepticism, the official statistics ranks the single market of twenty eight European nations as the world's greatest trading entity that surpasses the US and China in terms of produced services and goods (European Union, 2015).

Theoretically, these facts prove the main tenet posed by Francis Fukuyama (1995 cited in Fukuyama, 2013) in his famous The End of History and repeated twenty years later, where the author describes liberal democracy as the final stage of governmental development leading to greater economic prosperity 
and stability. At the same time, however, the recent global economic crisis showed us interesting facts: such countries as e.g. China where liberalism and democracy did not belong to the main agenda appeared to suffer from the breakdown to a lesser extent than the world's most prominent democratic countries (the US and most of the members of the EU) preserving greater growth rates and experiencing faster recovery.

Thus, the role of the European Union as the most advanced supranational business entity and the world's geo-economic leader does not seem to be an undisputable axiom. This paper aims at positioning the EU in a more precise way by using the concept of cultural dimensions developed by Geert Hofstede (1984). In the opinion of the author, the human paradigm viewed through the cultural strata may pose important limitations on Fukuyama's theory. This will ultimately represent the European Union in a rather unconditional (but perhaps more precise) way. At the same time, however, cultural aspects may explain economic situation in the EU and the mentioned countries with greater authoritarian tendencies more precisely.

\section{GEO-ECONOMIC ROLE OF THE EU}

As described before, statistically, the joint community of the twenty eight democratic nations forms the most significant economic power. This community produces more products and services than the rest of the countries in the world. Even though, according to Yang Jiang (2015), this might be seen rather as an exception than the rule, because the EU currently does not have any successful supranational analogue anywhere on the globe, the notorious proxy of the Soviet Union - a commonwealth of the 'free socialist republics' really proved the assumption expressed by Fukuyama, which described liberal democracies as the most effective and thus ultimate form of governmental development. Thus, while, according to the European Commission (2015), the EU is surpassing the US in terms of GDP, the Union also moves away from China:

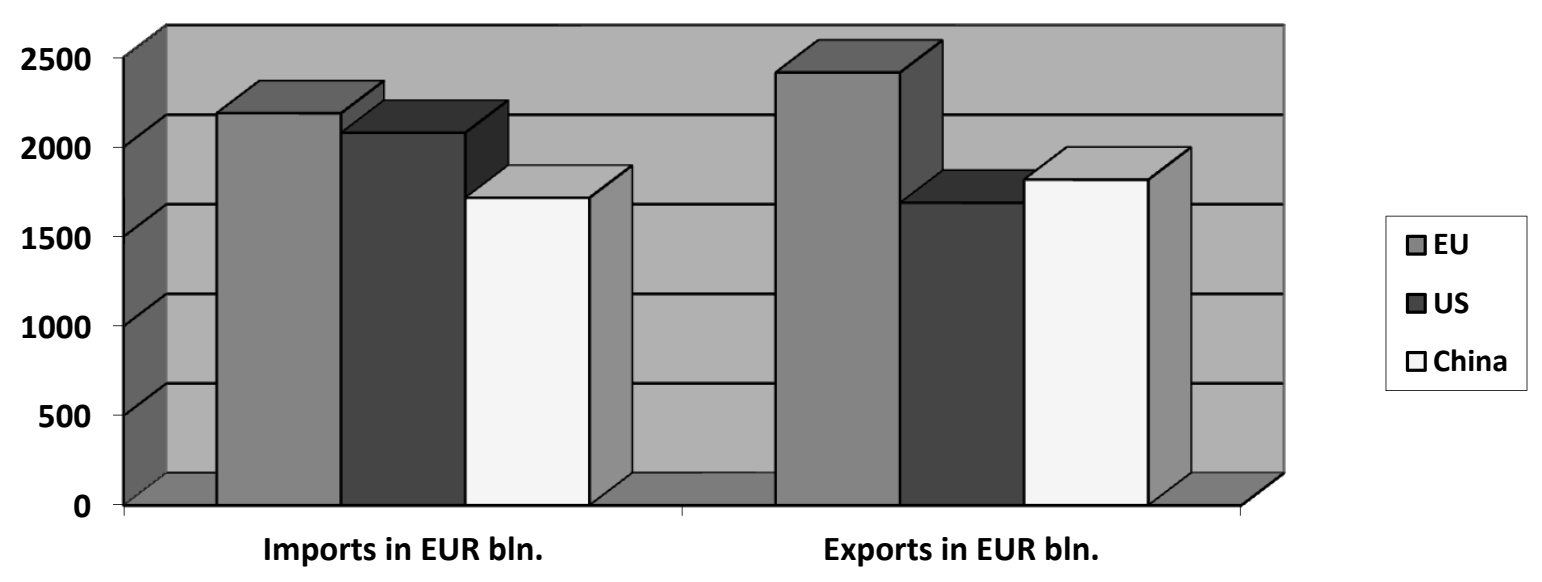

Fig 1. Comparative exports and imports in 2013

Source: European Commission (2015) 
At the same time, however, a particularly interesting point about the Chinese economy is that, in contrast to the EU and the US, it does not have deficit of its trade balance. In contrast, it experienced greater exports than imports throughout the initial and post-crisis periods. This fact seems to be particularly important if we consider the enormous size of the Chinese internal market. According to Huang Yasheng (2010), this demonstrates the advantages of the authoritarian economic system of China over the liberal Western model in times of crises. He also assumes uncontrolled markets to be less capable of rapidly addressing the downturn surges. In this context, state-controlled economies are viewed as more resilient and thus crisis-prone. Hence, the Washington Consensus - an embodiment of economic liberalism and classical economic theory per se - is assumed by such authors as Thomas Ambrosio (2014) to fall short within the uncertainties brought by the crisis. On the other hand, the Beijing Consensus and Keynesian methods associated with it are regarded as more appropriate and effective in such circumstances.

At the same time, Malcolm Warner (2015) sees Keynesianism as the only economic model capable of being driven in China in an efficient way. Albert Weale (2014), in his turn, regards liberal democracy as the core pillar of the European economic model. In such circumstances, the current paper aims at providing explanation for this phenomenon. It views the models through the prism of G. Hofstede's cultural dimensions and explains why each of them perfectly matches the cultural features of the respective nations and regions.

\section{KEYNESIANISM VS. CLASSICAL ECONOMIC THEORY: THROUGH THE PRISM OF HOFSTEDE'S CULTURAL DIMENSIONS}

When describing specific traits of different cultures, G. Hofstede (1984) focuses on six main antagonisms, suggesting them to be crucial for defining societal values and intentions. In his paper such notions as power distance (low vs. high), individualism vs. collectivism, masculinity vs. femininity, uncertainty avoidance (low vs. high), indulgence vs. restraint, long-term vs. short-term orientation are believed to be essential for understanding of underlining economic processes going on in the countries.

The author of this paper believes that, applicably to the economic regimes and governmental styles exercised along each of the viewed theoretical frameworks (Keynesianism and classical economic theory), some of the notions defined by G. Hofstede have their particular implication potential. Indeed, great power distance and strong sense of collectivism is what defines the Chinese culture, in the opinion of Y. Jiang (2015). In contrast to that, Weale (2014) describes European mentality as that possessing extremely strong feeling of individualism and striving for minimisation of power distance.

While using the facilities of the Hofstede Centre (2015) and comparing these dimensions of the 'founding fathers' and some of the soundest economies of 
the European Union with the ones associated with China, the difference seems to be vivid:

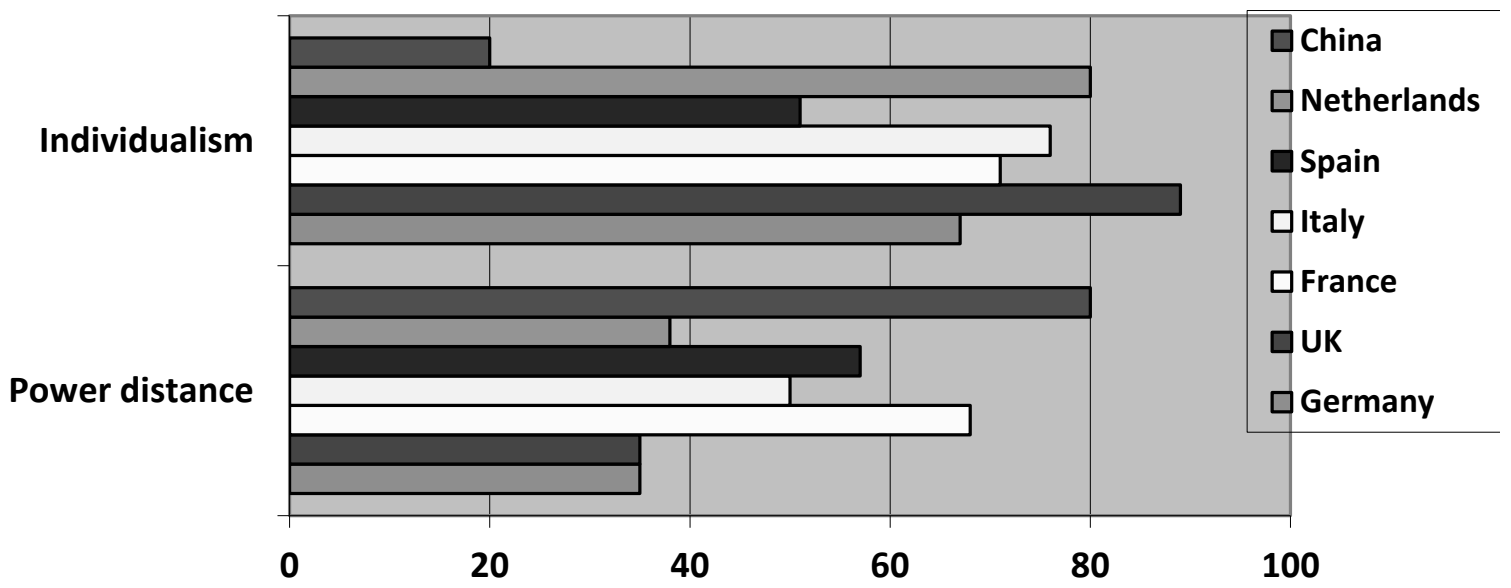

Fig.2. Magnitude of individualism and power distance in major European economies compared to China

Source: Hofstede Centre (2015)

Here, we can definitely spot the enormous dissonance between the high degree of individualism inherent in the European nations and immense sentiment towards collectivism in China. Additionally, China appears to be the nation with the greatest power distance which, in the opinion of Y. Jiang (2015) perfectly explains the ease of implementation of Keynesian methods that were introduced in the country's economy after the reforms of Deng Xiaoping. There, the reforms 'imposed' from the top were not regarded as something unnatural to the collective mind of the Chinese people due to that power distance factor and non-individualistic tradition of the national culture.

In the European Union, however, such an imposition of any governmental decisions potentially infiltrating personal welfare issues might sometimes be regarded as a violation of human rights and personal privacy (Weale, 2014). That is why statistical evidence has it that Keynesian methods of governmental economic regulation have never been popular among the population of Western democracies.

Thus, we can generalize some basic tenets of each theory and parallel them with two of the mentioned Hofstede's cultural dimensions so that liberal democracies and authoritarian economies will take different places:

\begin{tabular}{lll}
\hline Economic theory & Classical economic theory & Keynesianism \\
\hline Basic tenets & Consumer spending is essential & Governmental spending is vital \\
\cline { 2 - 3 } & $\begin{array}{l}\text { No need for the governmental } \\
\text { intervention in the market }\end{array}$ & $\begin{array}{l}\text { State monetary policy effects the } \\
\text { economy of private business }\end{array}$ \\
\hline $\begin{array}{l}\text { Economic policy } \\
\text { prescriptions }\end{array}$ & Washington Consensus & Beijing Consensus \\
\hline Countries & EU, US etc. & China, Vietnam etc. \\
\hline
\end{tabular}


In the opinion of the former head of the International Monetary Fund (StrossKahn, 2011 cited in Ramachandran, 2012), even though being quite a sound model in the past the Washington Consensus did not stand trial during the latest economic crisis. At the same time, some researchers such as e.g. Joseph Stiglitz (2002) started their critique of the principles even before the crisis, attributing most of the system shortcomings to its extreme simplification of the economic processes and thus transformation measures that are expected to be taken.

Does that mean that the EU economies will slightly move to a more authoritarian style while driving their national economies in the future? As the parallels with the theory of G. Hofstede show us, it does not seem to be the most predictable scenario if the cultural characteristics of the EU nations remain the same. At the same time, however, what will happen if the national content of the European countries will later undergo dramatic changes turning nations with some dominant European values into complete melting pots of multiculturalism?

\section{MULTICULTURALISM AND TWO RESPECTIVE ECONOMIC SCENARIOS}

Even though the authoritarian economic model might be more suitable for addressing global financial crises, long power distance and strong orientation towards collective achievement might not necessarily respond to the globalization concept. Nowadays liberal values of democratic countries and high living standards, despite rhetorical speeches of some authoritarian leaders, seem to be vividly attractive to most people. Indeed, the current refugee crises in Europe and Southeast Asia show us that people still tend to migrate to countries where a high standard of living goes alongside the personal freedom of each particular individual. That is actually why Thailand and not China happen to be the destination of most Rohingya migrants in Asia, as well as Germany and the UK are among the target countries for Syrian refugees coming to Europe.

Turning back to the Hofstede's dimensions and comparing the degrees of individualism and power distance in Germany, the UK, China and Syria, we can definitely spot a great contrast between the EU nations and the oriental countries:

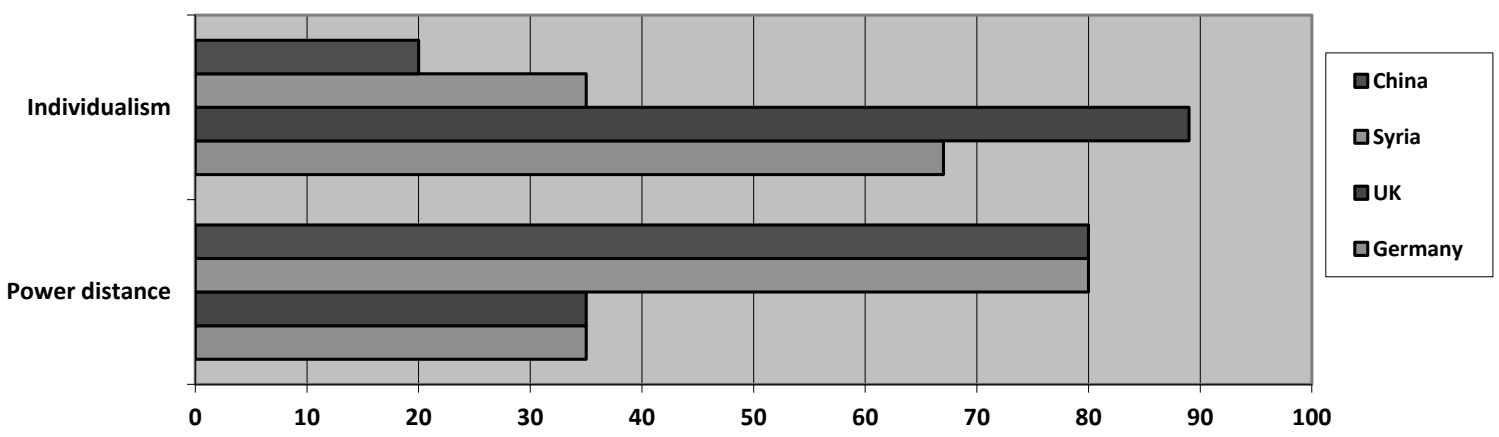

Fig. 3. Magnitude of power distance in China and Syria compared to the UK and Germany

Source: Hofstede Centre (2015) 
Interestingly, China and Syria share identical power distance while experiencing similarly high level of collectivism. This is strongly contrasting with both indicators shown for the UK and Germany. Nevertheless, despite such a great similarity in cultural dimensions, Syrian refugees tend to prefer culturally distant Germany and the UK.

In this case, the conduct of the refugees might seem 'irrational' or 'contradicting their cultural identity.' In the opinion of the author, however, this might highlight the other side of the authoritarian economic models. In particular, being presumably more capable of tackling economic crises, the model is less capable of providing sound social conditions for the unconstrained development of an individual as he or she is mainly regarded as a part of a system. Within the circumstances of globalization and universal promotion of personal success and prosperity, collective values might experience crisis leaving place for the individual ones.

What will that potentially mean for the future geo-economic role of the European Union? In the opinion of the author, this greatly depends on the capacity of the EU to integrate all the newly-incorporated cultures so that they will accept the common European values.

If this happens to be a successful undertaking, the union will get an immense increase in its population which, in compliance with the tenets of the classical economic theory, will basically mean stimulation of internal demand through greater consumer spending. Within the circumstances of absence of governmental intervention, this will potentially lead to further GDP growth and more rapid post-crisis rehabilitation. As the Chinese government is still hampering population increase, John Ravenhill (2005) considers immigration surges to the European Union a major asset towards turning the EU into the global geo-economic leader.

The alternative development scenario, however, may be less optimistic. In particular, if the incoming immigrants will fail to accept the prevailing European liberal democratic values, they might turn into a disintegrated part of society creating no added value and only consuming goods and services available in the EU. In such circumstances, the classical economic model will most likely fall short being incapable of supporting greater population with adequate amount of products etc. In the opinion of M. Warner (2015) this is when governmental levers need to be triggered so that participation of the citizens in the economic life of the country is intentionally maximized.

That is actually why the current refugee crisis may serve as a certain crossroads for the EU where, depending on the refugees' ability to integrate, the union might either follow the beaten track or dramatically change its liberal course for a more authoritarian one. In the opinion of the author, that choice may greatly determine the role of the European Union in the geo-economic world order either strengthening its position as a global leader or weakening it to the level of a constant runner-up. 


\section{CONCLUSION}

This paper represents an attempt to define the current role of the European Union in the global geo-economic order. Even though most of the quantitative indicators hint at its supreme prevalence as the first business power and thus the most successful world economy, viewing some unconditional dimensions of its interaction with the rest of the world such as e.g. cultural aspects might partially shatter that axiom.

Being a community of liberalized democratic economies, the EU does not favour strong governmental intervention into the business domain letting the principles of free economy prevail over an authoritarian way of addressing business challenges. On the other hand, China - a rapidly-growing nation with significant state control - represents an antagonist of the European Union. Even though the current GDP and trade balance indicators speak in favour of the EU model, the latest economic crisis showed greater resistance of authoritarian economies to the global business challenges. In the opinion of the author, such a practically proved factor may serve as an instigator for the European officials to stray from unconditional adherence towards liberalism in times of future economic challenges.

Having basically recovered from the crisis, the European Union currently faces a new unexpected challenge of incoming waves of refugees. As most of them come from the nations with less recognized liberal democratic values, such an influx of new potential citizens may significantly re-shape the economic models of the EU member states. That is why, the European Union's capacity to integrate new citizens will not only check Fukuyama's concept of liberal democratic governments as the final form of government for consistency, but will assess the union's economic survivability.

\section{REFERENCES}

1. Ambrosio, T. (2014). The Rise of the 'China Model' and'Beijing Consensus': Evidence of authoritarian diffusion?. Contemporary Politics, 18 (4), pp.381-399, DOI:10.1080/13569775.2012.728029, Retrieved September 18, 2015.

2. European Commission (2015). EU position in world trade. Retrieved September 18, 2015 from: http:/ / ec.europa.eu/trade/policy/eu-position-in-world-trade/

3. European Union (2015). Economy. Retrieved September 18, 2015 from: http://europa.eu/ about-eu/facts-figures/economy/index_en.htm

4. Fukuyama, F. (2013). The 'End of History' 20 Years Later. New Perspectives Quarterly, 30(4), pp. 31-39. DOI: 10.1111/npqu.11399, Retrieved September 18, 2015.

5. Hofstede, G. (1984). Culture's Consequences: International Differences in Work-Related Values. 2nd Edition. Beverly Hills, CA: SAGE Publications.

6. Hofstede Centre (2015) Countries: Cultural Dimensions. Retrieved September 18, 2015 from: http://geert-hofstede.com/germany.html

7. Jiang, Y. (2015) Vulgarisation of Keynesianism in China's response to the global financial crisis. Review of International Political Economy, 22 (2), pp.360-390. DOI:10.1080/09692290.2014.915227, Retrieved September 18, 2015.

8. Ramachandran, V. (2012) Global Development: Views from the Center: The Value of Rejecting Expert Advice. Retrieved September 18, 2015 from: http:/ / www.cgdev.org 
9. Ravenhill, J. (2005). Global Political Economy. $1^{\text {st }}$. Edition. Oxford, UK: Oxford University Press.

10. Stiglitz, J. (2002). Challenging the Washington Consensus. The Brown Journal of World Affairs, 9(2), pp. 33-40.

11. Warner, M. (2015). Keynes and China: Keynesianism with Chinese Characteristics. Asia Pacific Business Review, 21(2), pp. 251-263. DOI: 10.5873/AMV.2010.51627774, Retrieved September 18, 2015.

12. Weale, A. (2014). Citizenship in Europe and the Logic of Two-Level Political Contracts. German Law Journal, 15(5), pp. 867-881, DOI: 11.2707/1797726 Retrieved September 18, 2015.

13. Yasheng. H. (2010). Debating China's Economic Growth: The Beijing Consensus of the Washington Consensus. Academy of Management Perspectives, 24(2), pp. 31-47. DOI: 10.5465/ AMP.2010.51827774. Retrieved September 18, 2015. 